\title{
The Role of Physics Culture in Shaping In-Service Physics Teacher Identities and Framings of Equity: Two Case Studies
}

\author{
Clausell Mathis \\ Department of Physics, University of Washington-Seattle, Box 351560, Seattle, WA, USA, 910195-1560 \\ Amy D. Robertson \\ Department of Physics, Seattle Pacific University, 3107 Third Ave W, Seattle, WA, USA, 910119-1997
}

\begin{abstract}
Physics is perceived to have a culture of exclusion, which includes not embracing individuals from certain demographics who are underrepresented in the field. Many who are from underrepresented groups have stated they feel impacted by cultural pressures to assimilate to what is traditionally considered a "physics person." In order to better understand these cultural pressures this study examines statements from two physics teachers who participated in a summer professional development (PD) workshop. Throughout the summer PD, the two teachers made statements that described how physics culture impacted their identity and understanding of equity, which ultimately shaped their approach towards teaching. Analysis of teachers' statements showed that physics culture impacted the teachers' views on instruction in the areas of inclusivity and shaping students' physics identity. This study has implications for research on the role of physics culture and how it impacts underrepresented students' and teachers' identity and approach to equity.
\end{abstract}

\footnotetext{
2021 PERC Proceedings edited by Bennett, Frank, and Vieyra; Peer-reviewed, doi.org/10.1119/perc.2021.pr.Mathis Published by the American Association of Physics Teachers under a Creative Commons Attribution 4.0 license. Further distribution must maintain the cover page and attribution to the article's authors.
} 


\section{INTRODUCTION}

Science is often described as a culture that has a set of norms and practices, including discovery, critique, and debate of ideas $[1,2,3]$. All of these norms and practices are typical of physics and contribute to the creation of stereotypes about who is a "physics person." The common stereotype of a "physics person" is an eccentric, intelligent, male who is always focused on lab work and/or constructing theories [4]. This has created many concerns about who is embraced and wants to pursue careers in STEM $[4,5,6]$. Students may feel that they do not belong in the field, or even a physics class [7].

In many circumstances, underrepresented students in physics experience stereotype threat, where they feel threatened or at risk to conform to a stereotype, which then impacts their identity and performance [8]. Further, many underrepresented students report that physics culture excludes them in overt and covert ways [9]. However, underrepresented students may be hesitant to express these challenges because of the myth that physics is acultural, without bias or subjectivity [8].

Teachers' identities have also been influenced and/or impacted by these stereotypes, which can influence how they instruct and motivate their students [10]. Our study focuses on two case studies from teacher professional development to understand two physics teachers' experiences of physics culture and its influence on their physics identity and views towards equity.

\section{ANALYTICAL FRAMEWORK: PHYSICS CULTURE, IDENTITY, AND EQUITY}

There are aspects of physics culture that construct covert barriers for Students of Color if they remain in the discipline [11]. Within many environments, Students of Color are considered less than, marginalized, and isolated amongst their peers [12]. In addition, Students of Color are often not encouraged to pursue careers in physics or physics-related fields $[7,12]$. This can be through negative messaging from parents, counselors, and peers [7]. Overall, physics culture shapes the underrepresentation of certain groups in the discipline.

Physics is sometimes perceived as a subject to "weed out" students from marginalized groups and give a perception of a high academic status for more privileged students [12]. This can be perpetuated by teachers. In many cases, women and Students of Color feel neglected by physics teachers, who may have lower expectations based on stereotypes [13]. Additionally, marginalized groups may be perceived as not-belonging, and therefore not necessarily afforded the same opportunities. These biases against Students of Color affect whether and how they see themselves as physics people. Many Students of Color do not want to pursue careers in physics related fields because of cultural influences within physics spaces $[14,15]$.

Physics culture influences physics identity. A person's physics identity is how and whether someone sees themselves as a physics person [15]. Because of physics cultural norms, Students of Color feel marginalized and stereotyped on all fronts [11,17]. Some Students of Color experience constant overt and covert microaggressions that impact their physics identity [17]. These traumas can come from not being recognized for accomplishments, always being considered less than, having success be diminished, and being shunted away from opportunities [17]. Building a strong, positive physics identity for a Students of Color requires building resilience as they deal with these traumatic incidents during their education [12]. These traumatic impacts play a role in how a person navigates interactions within physics contexts $[17,18]$.

Given that some teachers also have traumatic experiences, they may have a different perspective on issues of equity and identity than those who have not. There is no single, accepted definition of equity. Commonly, people confuse equity with equality. According to Barajas-Lopez and Ishimanu [18], an equality perspective is believing that the playing field is even, whereas an equity view is an understanding that there are injustices that impact particular groups at the expense of others and pushing for strategies to resolve these injustices. Given that individuals have different experiences that impact their physics identity, there may be varying views on how to achieve equity. If a person has been through discrimination, prejudice, and marginalization within physics spaces, that person may view equity differently than someone who has not had those experiences. For the purposes of our study, we want to examine two teachers' experience within physics culture and how it shapes their identity and approach towards equity.

\section{METHODS}

Data collection for our study took place during a summer PD workshop for physics teachers. Twenty-two high school physics teachers participated (21 from the United States, 1 from Canada). The PD workshop took place over five days online. Within the five day workshop there were four guest facilitators of focused lessons, and three ongoing facilitators of welcome and debriefs. The main topics discussed during the workshop were energy representations, climate, intersectionality, and the Underrepresentation Curriculum [19]. Throughout the workshop there were breakout sessions where teachers had opportunities to reflect on their physics identity and cultural upbringing and influences, along with their views toward equity. The workshops were recorded by researchers who took field notes in real time.

For the purpose of this study, we are focusing on two participants from the summer PD, Javier and Rochelle, both pseudonyms. We selected these participants based on the 
statements they made about how physics culture had impacted their identity and thinking about equity.

Javier is an immigrant male high school physics teacher of El Salvadoran descent. He teaches in a low-income urban area in the western US. Before Javier became a teacher, he was an engineer, and he emphasized that many of his students did not know what an engineer was. Javier describes his upbringing as being "low-income" and "always having issues with access to ideas." Javier said his experiences had an impact on his decision to pursue teaching; he wants to use his past experiences to inspire students to consider pursuing STEM-related careers.

Rochelle is a white female high school physics teacher who teaches in a suburban area in the midwestern US. She describes herself as working in a very low socioeconomic school district with mostly Latinx and white students, and a small number of Black students. Rochelle described moments in her career where the pressure of being a woman impacted her physics identity - how she sees or saw herself as a physics person - and views toward equity.

We chose a case study because it was good for our research question in trying to identify mechanisms by which certain teaching and learning phenomena come to be, and for exploring the meaning of events for participants [20]. These mechanisms are often framed in terms of a process theory of cause (rather than an experimental one): A preceded $\mathrm{B}$, which preceded $\mathrm{C}$, which preceded $\mathrm{D}$, and these events are connected in a plausibly causal way [21]. In our cases, teachers name experiences within physics that shaped their identity and their views of equity, articulating a series of events that are plausibly causal and rooted in physics culture. We try to make those connections visible by providing direct quotes throughout.

The first author of this paper positions himself as an underrepresented physicist who is a former high school physics teacher. He is aware of the issues that were brought up by Rochelle and Javier, and he positions himself as a person who is attempting to understand the pressures placed upon underrepresented students. The second author is a disabled white woman who is emerging from a period of suppressing her expression of both of these identities in order to be seen as a full participant in the enterprise of physics [22]. She hopes that work like this will be a part of the transformation of the discipline toward more liberatory and inclusive practices.

\section{RESULTS}

We argue that physics culture impacts teachers' identity and the way they frame equity in their teaching. In this section, we substantiate this claim with quotes from Rochelle and Javier during reflection and breakout sessions of the summer PD.

\section{A. Rochelle}

Throughout the PD, Rochelle discussed how being a woman in physics impacted her self-efficacy and identity within physics culture. During a breakout session participants were asked to discuss moments that shaped their identity, Rochelle spoke on past experiences on how she viewed herself as a physicist:

"I think it was like maybe four years ago, I looked back at my undergraduate and graduate experience in physics and realized that I changed my identity quite a bit to fit into the physicist. And so, I was dressing like a boy, and that's fine for women to dress like boys, but it was like, it wasn't me. I was doing it to fit in. I also remember I made a lot of really awful comments about others, and like judged other women for wearing makeup and instead of just appreciating everyone and what they brought to the table, and I had to take a look back and be like, what am I doing?"

Rochelle's statements on judging other women for wearing makeup indicates she was influenced by narratives that physics is a masculine discipline, and that physics culture enforces social pressures for women to adapt to stereotypes of physicist personalities. Physics culture shaped how Rochelle saw herself within physics, i.e. her physics identity. Rochelle's statements imply that these pressures can occur in situations such as physics classes, where males may be more dominant in teacher-student interactions [23]. Males are more likely to take leadership roles in lab environments, where women take notes, or take a subordinate role [24]. This has caused many women to feel less valued, and in some cases disengage or remove themselves from these types of learning environments [24,25].

Physics culture also pressed Rochelle to identity shift, which is a subtle changing of language and behavior to avoid mistreatment [26]. In particular, Rochelle changed her appearance and took up a critical view towards the appearance of others. She now wants to use her experiences to empower women to be themselves, regardless of pressures placed on them to conform to a persona:

"No, I am, I am actually a woman, and I'm proud of it. ... and one thing that I do in my teaching is I like dress nice and feminine and not like weird,.... I think it's like shown [ing] girls in my school that they can look like however they want to and still enjoy physics...it was a very interesting like thought process that I had to go through"

Upon self-reflection, Rochelle had another identity shift towards being more empowered as a woman and encouraging more women to have confidence in their own identities. Similar to Rochelle, many women go through identity shifting by assimilating to physics culture to avoid being stereotyped [27]. For example, women may change how they appear, talk, or interact with other people in physics spaces [26,27]. Also, they may limit themselves in class or group discussions so as to not appear overbearing or 
dominant [26]. Physics culture can also have an opposite impact in that many women may feel pressured to overperform in order to resist or defy stereotypes [26]. Overall, there are external pressures placed upon women within physics culture to assimilate and compromise their image and identity in many aspects [28]. These stereotypes can play a role in how physics teachers influence women towards pursuing careers in physics.

Rochelle's experiences within physics culture influenced her to be an advocate for equitable physics instruction for women. Rochelle describes her classroom now as pushing students to reflect internally and discover who they are and how they fit within physics culture:

"When I teach physics, it's not about teaching physics, that's what I tell my students. They're going to learn physics, but I tell them it's about learning who they are and their identity and how it connects to their view."

\section{B. Javier}

During the PD, Javier talked extensively about how being an El Salvadoran immigrant impacted him. During a breakout section, where students talked about moments that impacted their identity, Javier discussed going into an immigration line and realizing he was different from all the other kids in the classroom. Javier stated that the intersection of being a minority within science and an immigrant impacted his philosophy of teaching:

"So, I am an immigrant from El Salvador. I actually became a citizen in the nineties actually right when I was starting college. and I didn't know, growing up, that I guess I was illegal. I had no idea, uh, growing up that that was my status and I was just living and, you know, being a kid and, you know, eventually, you know, going through the process of becoming a resident and a citizen, I realized, Oh wait a minute, you know, this is, uh, this is different, so I had to navigate, that experience, and that shaped my approach to how I work with my students. Definitely, so I have this, you know, this dual, I guess, this identity of being Salvadoran and being an American."

In this quote, Javier says that his experience of being seen as different has shaped his "approach to how [he] work[s] with students."

Later, Javier spoke about how his experience as an engineer propelled him to change careers. He stated that he was one of the only Latino people at his engineering firm, and he understood how it felt to constantly experience imposter syndrome. Because of these experiences, Javier realized there was an issue with access to ideas in minoritized and low-income communities. Later in the week, Javier described how his experiences shaped his view towards equity.

"I guess since I started teaching, just building on my experiences,... as an engineer and,... as a Latino, firstgeneration for my family in college, I have always found it valuable to build identity in my students. I guess my conflict is: what type of identity I want to build from them? ... My experiences might be completely different to theirs but just giving them a sense of,... you know, a lot of the times, we talk about this in my class in terms of this idea of the imposter syndrome, that we might carry as, you know, my students go into college or they become successful and, you know, what does that mean? And what does that represent and why does that develop in us? ... And you know, for me, when I am in physics, I tell them you're going to learn physics, but we're going to learn like, what's your identity within the framework of physics? Like who you are like? You know, what, what do you believe in?, what do you want to address within the lens of physics?"

Because of Javier's experiences, he prioritizes building a strong physics identity within students. He realized that many of his students will experience judgement and discrimination. In order to prepare and counter potential discrimination, Javier wants to help students see the value they bring to physics culture, with the goal of instilling a positive identity and self-efficacy.

In another quote, Javier discussed how some of his female students are influenced to not pursue engineering careers:

"And, you know, it gets interesting because we touch on concepts of sexism, ...., the girl wants to be an engineer and the parents, you don't want to be an engineer. You're a girl that is not your role .... Also, these conflicts I have with parents when I have to talk to them, ...she's awesome. She should continue. So, I guess for me, it's building that identity within students, and then the internal conflicts of sometimes with families that I have to work with ... shift their thinking of what it means for a Latino to be in as a scientist or as an engineer."

Javier understands that there are external influences on women who want to be in science that can deter them from pursuing their interests. Due to these external influences, Javier tries to not only build student identity, but at times talks to parents, hoping to "shift their thinking" around who can be a scientist or an engineer.

Javier's experiences align with those of many People of Color, in that intersectionality plays a role in how they negotiate multiple social identities, within an environment that traditionally does not have many People of Color. Feelings of not belonging, ostracization, and being questioned about their intelligence are common occurrences for People of Color in physics spaces [12,28].

\section{CONCLUSION AND DISCUSSION}

Javier's and Rochelle's experiences within physics culture indicate that a person's individual and social identity such as race, class, and gender, can impact their engagement with science. Both participants' experiences within physics culture shaped their physics identity and motivated them towards equitable approaches in their teaching. Statements 
from Rochelle and Javier show ways in which physics culture impacts teachers' equitable approaches to instruction. In the case of Rochelle, physics culture played a role in how she viewed herself in the physics context, and she wants to use that experience as a way to encourage women to be more confident in themselves and to assert themselves as physics people. Rochelle believed her college experience caused her to work towards informing women that they don't need to change their identity to be accepted within physics spaces. Rochelle's statements on judging other women for wearing makeup indicates she was influenced by narratives that physics is a masculine discipline. Rochelle's experience aligns with a study from Francis et al. [33], which describes the view of physics being perceived as a masculine discipline into five common narratives: (1) certain disciplines are stereotyped as masculine or feminine; (2) women and men are naturally drawn to certain disciplines; (3) feminine disciplines are superficial, (4) masculine disciplines are sophisticated; (5) femininity is conducive to masculine work. This calls to attention that women may benefit from unique support when entering physics spaces to counteract the specific cultural pressures placed upon them.

Rochelle's experiences in physics culture and her evolution towards becoming more equitable in her instruction, suggest the importance of encouraging teachers to self-reflect on how physics culture influenced their view of themselves as physics people and towards others who may be underrepresented, and using those experiences to influence their approach towards equitable instruction. Rochelle's case illustrates the importance of teachers being cognizant of the influences of physics culture, and then working to resist projecting the negative influences upon other students.

Javier's experiences growing up as an immigrant and working as the only Latino engineer propelled him to teach, and to inspire his students to build identities as physics people. His experience of imposter syndrome while being underrepresented in engineering had an impact on his teaching. Javier also understands that physics culture puts pressure on women to deter away from physics related careers. To counter these influences, Javier at times works with parents to encourage their daughters to pursue careers in physics or physics related fields.
Findings from our study build on existing studies showing that physics culture influences how people marginalized by physics develop physics identity [12], and that teachers' identities influence their subsequent teaching decisions. Existing work highlights the role that formative teacher education experiences can have on the development of physics teacher identity [30]. Our work adds to this, showing some of the formative experiences within physics culture that shaped two in-service physics teachers' identities and views toward equity. In particular, these two cases make visible not only some of the ways in which the culture of exclusion within physics shapes teachers' views of themselves, but also ways in which teachers resist and transform in response [31]. In so doing, these teachers are participating in the re-creation of physics and physics teaching, toward more inclusive classroom practices, including supporting students in developing a positive physics identity. Literature indicates that strong pre-college science experiences, teacher encouragement, perseverance, and intrinsic motivation all play a vital role in People of Color's success in science after high school [25,32]. Additionally, at times, the role of teachers in supporting students' engagement in science is believed to be more important than that of parents [27]. Many teachers express lower expectations for Students of Color [23].

This study calls for attention to the complexities of how physics culture impacts teachers' personal, social, and political conceptions of themselves and their practice. In addition, we ask for physics teachers to support students who may feel isolated and pressured by stereotypes or bias against them. Discrimination may be happening intentionally or unintentionally. Teachers can create cultures and environments where students can feel free to express themselves and maximize their potential. Further studies on the impact of physics culture on teacher practices are needed.

\section{ACKNOWLEDGMENTS}

We would like to thank the teacher participants in the summer PD, for their work and participation. Additionally, I would like to thank the other researchers on the energy and equity team: Rachel Scherr, Jessica Hernandez, Tra Huynh, Kara Gray, Lauren Bauman, and W. Tali Hairston This research was supported by the National Science Foundation DRL 1933601.
[1] G. S. Aikenhead, Stud Sci Educ 27, 1-52 (1996).

[2] M. N. Maddock, Stud Sci Educ 10:1, 1-26 (19101).

[3] M. J. Feuer, L. T. Towne, and R. J. Shavelson, Educ. Res. J. 9, 4-14. (2002).

[4] G. D. Wilson, and C. Jackson, Pers. Individ. Differ. 16, 11071109. (1994).

[5] Z. Hazari, R. H. Tai, and P. M. Sadler, Sci. Educ. 91, $1047-$ 1076. (2007).
[6] Z. Kalender, E. Marshman, C. D. Schunn, T. J. Nokes-Malach, and C. Singh, Phys. Rev. Phys. Educ. Res. 15, 0201410. (2019).

[7] Z. Hazari and C. Cass, Phys Teach. 56, 442-446. (20110).

[8] C. Steele. Am Psychol 53, 680-681. (1998).

[9] K. Rosa and F.M. Mensah. Phys. Rev. Phys. Educ. Res 12, 020113. (2016).

[10] H. R. Milner and A. W. Hoy, Teach Teach Educ. 19, 263276. (2003). 
[11] H. Y. Chang, J. N. Kohler, J. E. Ard, and C. Mathis, Univers. J. Educ. Res. 6, 2492-2497. (20110).

[12] S. Hyater-Adams, C. Fracchiolla, T. Williams, N. Finkelstein, and K. Hinko, Phys. Rev. Phys. Educ. Res. 15, 020115. (2019).

[13] J. Mervis, Science (New York, NY) 334, 1333. (2011).

[14] Z. Hazari, E. Brewe, R.M. Goertzen, and T. Hodapp. Phys Teach 55, 96-99. (2017).

[15] C. E. Horna and A. J. Richards, Phys Teach 56, 4410451.(20110).

[16] L.T. Ko, R. R. Kachchaf, A.K. Hodari, and M. Ong. J Women Minor Sci Eng 20, 171-195. (2014).

[17] Z. Hazari, G. Sonnert, P.M. Sadler, and M. Shanahan. J Res Sci Teach 47, 9710-1003. (2010).

[18] F. Barajas-López and A. M. Ishimaru. ““'Darles el lugar”: A place for nondominant family knowing in educational equity." Urban Educ. 55, 310-65. (2020).

[19] A. Daane. Bull. Am. Phys. Soc. (2020).

[20] F. Erickson. Qualitative Methods in Research on Teaching". (Institute for Research on Teaching, New York, NY, 19105), p. $119-162$

[21] J.A. Maxwell. Field methods, 16, 243-264. (2004).

[22] M. Ong. Soc. Probl. 52, 593-617. (2005).

[23] E. Gillibrand, P. Robinson, R. Brawn, and A. Osborn. Int. J. Sci. Educ 21, 349. (1999).

[24] E. Maccoby. The Two Sexes: Growing Up Apart,Coming Together (Belknap Press, Cambridge, MA, 19910).

[25] H. B. Carlone. J. Res. Sci. Teach. 41, 392. (2004).

[26] M.S. Jones, V. Womack, G. Jérémie-Brink, and D.D. Dickens. Sex Roles 1-11. (2021).

[27] Z. Hazari, R.H. Tai, and P. M. Sadler. Sci. Educ., 91, $1047-$ 1076. (2007).

[28] M. Ong. Soc. Probl. 52, 593-617. (2005).

[29] B. Francis, L. Archer, J. Moote, J. DeWitt, E. MacLeod, and L. Yeomans. Sex Roles. 76, 156-174. (2017).

[30] E. W. Close, J. Conn, and H. G. Close. Phys. Rev. Phys. Educ. Res. 12, 010109. (2016).

[31] H. Giroux. Harv. Educ. Rev. 53, 257-293. (19103).

[32] M. Ong, C. Wright, L. Espinosa, and G. Orfield. Harv. Educ Rev. 10, 172-209. (2011) 